\title{
NAT2 Gene Polymorphisms and Plasma Isoniazid Concentration in Vietnamese Tuberculosis Patients
}

\author{
Tuan Anh LE ${ }^{\#}$, Nhung Hong Thi PHAM", Long Doan DINH, \\ Luyen Thi LE and Thom Thi VU*
}

School of Medicine and Pharmacy, Vietnam National University, Ha Noi, Viet Nam

('Corresponding author's e-mail: thomtbk5@gmail.com)

Received: 6 March 2019, Revised: 28 November 2019, Accepted: 17 December 2019

\begin{abstract}
Isoniazid (INH) is one of the most common drugs for tuberculosis (TB) treatment and INH acetylation catalyzed by non-inducible hepatic enzyme arylamine $\mathrm{N}$-acetyltransferase type 2 (NAT2). The isoniazid acetylation rates, which depend on NAT2 genotypes, is constant in an individual but can changes between patients. Phenotypic groups can be classified based on the genotype: slow, intermediate, and rapid acetylators. This study was performed to identify the relation between NAT2 gene polymorphisms and plasma INH concentrations among the different genotypes of Vietnamese tuberculosis patients. Blood samples of 136 adult TB patients treated with INH were collected and genotyped for NAT2 gene polymorphisms using Sanger sequencing. Two-hour post-dosing INH plasma concentrations were determined by high-performance liquid chromatography/tandem mass spectrometry (HPLC/MS/MS). Among the 136 patients genotyped, there were 43 (31.62\%), 58 (42.65\%), and 35 (25.74\%) of slow, intermediate, and rapid acetylation phenotypes, with two-hour post dosing INH plasma concentrations of $3.4,2.7$, and $2.2 \mu \mathrm{g} / \mathrm{ml}$, respectively. The differences in INH concentrations among the three genotypes were significant $(\mathrm{P}<0.05)$. Genotyping of TB patients from Vietnam for NAT2 gene polymorphism revealed that 48 percent of the study population comprised slow acetylators. Two-hour INH levels were significantly different among CC and TT homozygous genotypes of NAT2(C282T), as $2.7 \mu \mathrm{g} / \mathrm{ml}$ and 3.9 $\mu \mathrm{g} / \mathrm{ml}$, respectively. This suggests that $N A T 2(\mathrm{C} 282 \mathrm{~T})$ could play a role in INH metabolism in TB patients.
\end{abstract}

Keywords: N-acetyltransferase 2 enzyme, NAT2 polymorphisms, Isoniazid, Tuberculosis

\section{Introduction}

Worldwide, tuberculosis (TB) is an infectious disease with the highest mortality; millions of people continue to fall sick with the disease each year. Vietnam ranks $16^{\text {th }}$ among 30 high $\mathrm{TB}$ burden countries, with an estimated incidence of 124 new cases per 100,000 people in 2017 [1]. Isoniazid (INH) is a key agent and is widely used in TB treatment and prevention. The antimicrobial activity of INH is selective for Mycobacterium tuberculosis. The major pathway for metabolizing INH involves acetylation to acetyl INH, catalyzed by hepatic and intestinal enzyme N-acetyltransferase 2 (NAT2). This metabolism can create many hepatotoxic products, such as hydrazine and acetyldiazen. Despite the rather successful therapeutic effects with INH, there are still treatment failures and uncontrolled adverse effects (most commonly, liver injury and, occasionally, mortality) [1].

During the last ten years, personalized medicine has received lot of attention from scientists with the aims of giving each individual patient a precise medical treatment. Using inexpensive gene testing, such

\footnotetext{
${ }^{\#}$ Equal contribution
} 
http://wjst.wu.ac.th

as direct PCR, many gene variants have been identified to support the treatment of non-infectious diseases, like psoriatic arthritis, or infectious disease, such as tuberculosis [2]. In tuberculosis treatment, the INH acetylation rate varies between patients, and is divided into three phenotypic groups: slow, intermediate, and rapid acetylators [3]. Several clinical reports have shown that slow acetylators have a higher risk of INH-induced liver injury in different populations [4]. In contrast, treatment failure usually occurs in rapid acetylators [5]. NAT2 activity status is controlled by haplotypes composed of several single nucleotide polymorphisms (SNPs) in the NAT2 gene [6,7]. The NAT2 gene is located on chromosome $8 \mathrm{p} 22$, with a single open reading frame of $870 \mathrm{bp}$. Generally, single nucleotide substitutions in NAT2 usually lead to low N-acetylation activity, decreased NAT2 expression, or enzyme instability. The wild type $N A T 2 * 4$ allele, which has no single nucleotide substitutions in NAT2, is associated with the rapid acetylator phenotype. The acetylation phenotype can be predicted through the genotype of some SNPs, including missense SNPs (T341C, G590A, A803G and G857GA) and silent SNPs (C282T and C481CT) $[4,8]$.

Studies of the effect of NAT2 genotypes on INH metabolism can improve the effectiveness of treatment, while the adverse effects associated with this drug can be minimized [9]. Previous studies in other populations have reported an association of NAT2 genotypes with INH acetylation; however, this association has never been reported in Vietnam. INH acetylation and NAT2 genotypes data can be used to improve the quality of TB management and to decrease the risk of INH toxicity in TB treatment. In this present study, we investigated the various NAT2 genotypes found among Vietnamese tuberculosis patients and compared plasma INH concentrations among these different genotypes.

\section{Materials and methods}

\section{Patients}

TB patients were recruited from the National Lung Hospital, Hanoi Lung Hospital, and 74 military hospitals during March 2014 to September 2018. Patients were eligible to take part in this study if they met the following criteria: (i) aged 16 years or above; (ii) initial diagnosis: new and retreatment TB patients; (iii) indications for Isoniazid, and (iv) inpatient treatment at the hospital. This study was approved by the ethics committee of the School of Medicine and Pharmacy, Vietnam National University Hanoi, coding number IRB-VN01016. Our study was composed of 136 TB patients. Venous blood samples were collected in tubes containing ethylenediamine tetraacetic acid (EDTA) for NAT2 genotyping, and in heparinized tubes after an oral administration of $5 \mathrm{mg}$ of isoniazid per $\mathrm{kg}$ of body weight (Isoniazid Tablets BP100 mg, Macleods Pharmaceuticals Ltd.) to determine the INH concentration.

\section{NAT2 genotyping}

Genomic DNA was extracted from blood samples by using the E.Z.N.A blood DNA Mini Kit (Omega-Biotek Inc., USA) according to the manufacturer's recommended procedure. The extracted DNA products were analyzed on a $1 \%$ agarose gel and measured at $\mathrm{OD}_{280}$ and $\mathrm{OD}_{260}$ on a NanoDrop 2000 spectrophotometer (NanoDrop Technologies Inc., USA). The fragment $1093 \mathrm{bp}$ of the NAT2 gene was amplified by PCR with a pair of specific primers (5'-GGA ACA AAT TGG ACT TGG-3' and 5'-TCT AGC ATG AAT CAC TCT GC-3'). PCR mixture was composed of $20 \mathrm{ng} / \mu \mathrm{l}$ DNA template, $0.5 \mu \mathrm{M}$ of each primer (Phusa Biochem Inc., Vietnam), and Kapa 2GTM Robust HotStart ReadyMix 2x (Kapa Biosystems Inc., USA). PCR program settings included preheating at $95{ }^{\circ} \mathrm{C}$ for $3 \mathrm{~min}$, 35 cycle of $95{ }^{\circ} \mathrm{C}$ for $10 \mathrm{~s}, 57{ }^{\circ} \mathrm{C}$ for $15 \mathrm{~s}, 72{ }^{\circ} \mathrm{C}$ for $60 \mathrm{~s}$, and then extension at $72{ }^{\circ} \mathrm{C}$ for $10 \mathrm{~min}$. PCR product quality was tested on $1.5 \%$ agarose gels electrophoresis. Next, the PCR products were purified by PCR E.Z.N.A® Cycle-Pure Kit (Omega-Biotek Inc., USA) and sent for sequencing (1st Base Laboratories Sdn. Bhd., Malaysia). Sequence analysis was performed by a BLAST search in the GenBank database (http://www.ncbi.nlm.nih.gov) and BioEdit version 7.1.9 software, thereby identifying the patient's genotype. 


\section{Plasma isoniazid (INH) estimation}

This analysis was carried out within a week of sample collection, by high-performance liquid chromatography/tandem mass spectrometry (HPLC/MS/MS) using a validated method [10]. A mobile phase containing methanol and ammonium acetate $5 \mathrm{mM}, \mathrm{pH} 3.5$ and a Gemini $\mathrm{C} 18$ column were used for HPLC. Precision of this measurement was $<15 \%$, estimated by the coefficient of variation. The linear range of the calibration curve was $0.1-10 \mu \mathrm{g} / \mathrm{ml}$, and the lower limit of quantification was 0.1 $\mu \mathrm{g} / \mathrm{mL}$.

\section{Data analysis}

The slow, intermediate, and rapid NAT2 acetylator phenotypes were determined using the NAT2PRED web server (Kuznetsov et al. [8]). This software allows the use of the six SNP (T341C, G590A, A803G, G857A, C282T, and C481T) in NAT2 to eventually determine the acetylator phenotype. The haplotypes and their frequencies were carried out by SNP Analyzer version 2.0 software (ISTECH, South Korea) (Yoo et al. [11]). Statistical analysis was performed using SPSS version 22.0 software (SPSS Inc., USA). Data were expressed as median and inter-quartile range (IQR). One-way ANOVA with Tukey post hoc test were performed to compare differences in two-hour INH concentrations among the different genotypes. Chi-square test was utilized for comparison of categorical variables among groups. The analysis was statistically significant if $p$-value $<0.05$.

Table 1 Comparison of minor allele frequencies of SNPs located on NAT2 gene in different populations of the world.

\begin{tabular}{|c|c|c|c|c|c|c|c|}
\hline & \multicolumn{7}{|c|}{ Research subject populations in the world } \\
\hline & $\begin{array}{l}\text { Present study } \\
\quad(n=136)\end{array}$ & $\begin{array}{c}\text { Kinh in HCM city, } \\
\text { Vietnam } \\
(\mathrm{n}=198)\end{array}$ & $\begin{array}{c}\text { East Asian } \\
(n=504)\end{array}$ & $\begin{array}{c}\text { South Asian } \\
(\mathrm{n}=\mathbf{4 8 9})\end{array}$ & $\begin{array}{c}\text { African } \\
(\mathrm{n}=661)\end{array}$ & $\begin{array}{c}\text { European } \\
(\mathrm{n}=\mathbf{5 0 3})\end{array}$ & $\begin{array}{c}\begin{array}{c}\text { American } \\
(n=347)\end{array} \\
\end{array}$ \\
\hline \multicolumn{8}{|l|}{ C282T (rs1041983) } \\
\hline Allele $\mathrm{T}$ frequency & 0.47 & 0.54 & 0.44 & 0.43 & 0.47 & 0.31 & 0.29 \\
\hline \multicolumn{8}{|l|}{ T341C (rs1801280) } \\
\hline Allele $\mathrm{C}$ frequency & 0.06 & 0.06 & 0.04 & 0.35 & 0.29 & 0.45 & 0.36 \\
\hline \multicolumn{8}{|l|}{ C481T (rs1799929) } \\
\hline Allele $\mathrm{T}$ frequency & 0.06 & 0.05 & 0.04 & 0.32 & 0.24 & 0.44 & 0.34 \\
\hline \multicolumn{8}{|l|}{ G590A (rs1799930) } \\
\hline Allele A frequency & 0.32 & 0.35 & 0.26 & 0.36 & 0.24 & 0.28 & 0.17 \\
\hline \multicolumn{8}{|l|}{ A803G (rs1208) } \\
\hline Allele $\mathrm{G}$ frequency & 0.06 & 0.06 & 0.04 & 0.36 & 0.39 & 0.44 & 0.37 \\
\hline \multicolumn{8}{|l|}{ G857A (rs1799931) } \\
\hline Allele A frequency & 0.16 & 0.19 & 0.18 & 0.07 & 0.03 & 0.02 & 0.11 \\
\hline
\end{tabular}

\section{Results and discussion}

The results of the minor allele frequency of SNPs located on the NAT2 gene are presented in Table 1. In the analyzed loci, the frequencies of genotypes followed Hardy-Weinberg expectations. This means that the genetic compositions of these alleles were quite balanced, at least in 136 individuals of this study. Compared to the genome project in Phase 3, conducted on 2,504 people in 26 countries worldwide, including Kinh people living in Ho Chi Minh City (Vietnam) (1,000 Genomes Project Phase 3 Data, 2018), our results are similar to those of the research on Kinh people and East Asian $(p>0.05)$. Kinh 
http://wjst.wu.ac.th

people, also known as "Vietnamese people", account for nearly $90 \%$ of the population of Vietnam, and allelic frequencies of NAT2 gene obtained from this group could represent normal Vietnamese people. The similarity in the NAT2 allele frequencies in the normal group and the TB patient group is evidence that NAT2 is not a tuberculosis susceptibility gene. Compared with the South Asian population, the frequency of the minor alleles of $\mathrm{A} 803 \mathrm{G}$ in the present study and in the East Asian population was lower, with statistically significant difference $(p<0.05)$; however, the minor alleles of G857A is highest compared to other populations, and two times higher than the South Asian population.

Table 2 Observed frequencies of NAT2 haplotypes in Vietnamese tuberculosis patients $(\mathrm{n}=136)$.

\begin{tabular}{|c|c|c|}
\hline NAT2 haplotype & SNP & Observed frequency $(\%)$ \\
\hline$N A T 2 * 4$ & None & 46.22 \\
\hline$N A T 2 * 5 \mathrm{~A}$ & $\mathrm{~T} 341 \mathrm{C}, \mathrm{C} 481 \mathrm{~T}$ & 0.37 \\
\hline$N A T 2 * 5 B$ & T341C, C481T, A803G & 5.52 \\
\hline$N A T 2 * 5 \mathrm{E}$ & T341C, C481T, G590A & 0.37 \\
\hline Total $N A T 2 * 5$ & & 6.26 \\
\hline$N A T 2 * 6 \mathrm{~A}$ & C282T, G590A & 30.20 \\
\hline$N A T 2 * 6 \mathrm{~J}$ & C282T, G590 A, G857A & 1.02 \\
\hline Total $N A T 2 * 6$ & & 31.22 \\
\hline$N A T 2 * 7 \mathrm{~B}$ & C282T, G857A & 14.50 \\
\hline$N A T 2 * 7 \mathrm{C}$ & $\mathrm{C} 282 \mathrm{~T}, \mathrm{~A} 803 \mathrm{G}, \mathrm{G} 857 \mathrm{~A}$ & 2.22 \\
\hline Total $N A T 2 * 7$ & $\mathrm{C} 481 \mathrm{~T}$ & 16.72 \\
\hline$N A T 2 * 12 A$ & A803G & 0.46 \\
\hline$N A T 2 * 13 \mathrm{~A}$ & $\mathrm{C} 282 \mathrm{~T}$ & 1.12 \\
\hline
\end{tabular}

A haplotype is a particular pattern of alleles at sequential loci on a single chromosome. In order to reconstruct haplotypes from the unphased diploid genotype data, we used NAT2PRED web server with EM-based algorithm [11]. Ten different haplotypes found among Vietnamese tuberculosis patients are presented in Table 2 . The major alleles found were $N A T 2 * 4, * 6 \mathrm{~A}$, and $* 7 \mathrm{~B}$, followed by $N A T 2 * 5 \mathrm{~B}, * 6 \mathrm{~J}$, $* 7 \mathrm{C}$, and *13A. Additionally, some alleles were observed at frequencies below $1 \%(N A T 2 * 5 \mathrm{~A}, * 5 \mathrm{E}$, and $* 12 \mathrm{~A})$. The distribution of the NAT2 genotype frequencies and predicted phenotypes are summarized in Table 3. Among genotypes, $N A T 2 * 4 / * 4$ was the most frequent genotype $(25.74 \%)$. The most frequent slow and intermediate acetylator genotypes observed were $N A T 2 * 6 / * 6(13.24 \%)$ and $N A T 2 * 4 / * 6(23.53$ $\%)$, respectively. The results of this study are consistent with the general trend of Asian haplotype distribution. Asian populations displayed lower haplotype diversity than either European or African populations. The mean haplotype diversities were estimated to be $0.59 \pm 0.11,0.69 \pm 0.04$ and $0.79 \pm$ 0.06 in East Asians, Europeans, and Africans, respectively. Twenty-six haplotypes of NAT2 genes were determined; only a few major haplotypes were found in Asian populations- NAT2*4, NAT2*6A and $N A T 2 * 7 \mathrm{~B}[12]$.

T341C, G590A, and G857A are the main SNPs which lead to reduced NAT2 activity; many studies have only analyzed these 3 SNPs to predict acetylation phenotype. In particular, phenotypic groups can be classified based on the number of mutant alleles: rapid acetylators with no SNPs (homozygous for wild type $N A T 2 * 4$ allele), intermediate acetylators with heterozygous for $N A T 2 * 4$ and a mutant allele, and slow acetylators with a combination of mutant alleles [3]. 134/136 patients had the same predicted 
http://wjst.wu.ac.th

phenotype results, based on genotypes of 3 SNP and 6 SNP, using NAT2PRED web server. The remaining two patients, who had only $\mathrm{C} 282 \mathrm{~T}$ mutation, were predicted to be rapid acetylator using 3 SNP, and intermediate acetylator using 6SNP. If all six SNPs are used, it is reported that the predictor can achieve an accuracy of $99.9 \%$, with sensitivities and specificities from 99.6 to 100 . If data on two synonymous $\mathrm{C} 282 \mathrm{~T}$ and $\mathrm{C} 481 \mathrm{~T}$ are removed, the accuracy of the prediction drops from 99.9 to $93.2 \%$ [8]. In fact, the number of slow acetylators who are at increased risk of adverse effects is almost larger than that of rapid acetylators (1,000 Genomes Project Phase 3 Data, 2018). So, at-risk individuals can be missed when the accuracy of the prediction decreases. Therefore, we conclude that six SNPs used in the present study are required to faithfully identify the acetylator phenotype.

Table 3 Distribution of NAT2 genotypes and predicted acetylator phenotype $(\mathrm{n}=136)$.

\begin{tabular}{|c|c|c|c|}
\hline Genotype & Number of subjects & Observed frequency $(\%)$ & Predicted phenotype \\
\hline$N A T 2 * 5 / * 5$ & 1 & 0.74 & Slow \\
\hline$N A T 2 * 5 / * 6$ & 4 & 2.94 & Slow \\
\hline$N A T 2 * 5 / * 7$ & 2 & 1.47 & Slow \\
\hline$N A T 2 * 6 / * 6$ & 18 & 13.24 & Slow \\
\hline$N A T 2 * 6 / * 7$ & 12 & 8.82 & Slow \\
\hline$N A T 2 * 7 / * 7$ & 6 & 4.41 & Slow \\
\hline Total & 43 & 31.62 & Slow \\
\hline$N A T 2 * 4 * 5$ & 9 & 6.62 & Intermediate \\
\hline$N A T 2 * 4 * 6$ & 32 & 23.53 & Intermediate \\
\hline$N A T 2 * 4 * 7$ & 13 & 9.56 & Intermediate \\
\hline$N A T 2 * 4 * 13$ & 2 & 1.47 & Intermediate \\
\hline$N A T 2 * 6 * 12$ & 1 & 0.74 & Intermediate \\
\hline$N A T 2 * 7 * 13$ & 1 & 0.74 & Intermediate \\
\hline Total & 58 & 42.65 & Intermediate \\
\hline$N A T 2 * 4 / * 4$ & 35 & 25.74 & Rapid \\
\hline
\end{tabular}

The median two-hour INH concentrations in slow, intermediate, and rapid acetylators were 3.4, 2.7, and $2.2 \mu \mathrm{g} / \mathrm{ml}$, respectively. The differences in INH concentrations among the three genotypes were significant $(p<0.05)$. There existed a significant trend in the INH concentrations among the genotypes; the slow acetylators had the highest concentration, followed by the intermediate acetylators, and rapid acetylators had the lowest INH concentration (Figure 1A). Among 6SNP, the C282T genotype significantly affected INH concentration (Figure 1B). Patients with homozygous CC of C282T had a two-hour INH concentration median of $2.7(1.4-3.6) \mu \mathrm{g} / \mathrm{ml}$, which was significantly lower than patients with homozygous TT, which was $3.9(2.6-4.4) \mu \mathrm{g} / \mathrm{ml}$.

The metabolism of INH could be affected by variations in the NAT2 gene among different populations. Specifically, several studies have reported the influence of NAT2 genotypes on plasma INH concentrations, as well as INH-induced hepatotoxicity $[13,14,15,16]$. In general, significant variations in INH concentrations among different genotypes is an important subject, since INH is a first line TB drug and is widely used in Vietnam. Slower acetylators with higher concentrations of INH have a higher risk of drug-induced hepatotoxicity. A meta-analysis from 37 studies, comprising 1527 cases and 7184 controls, showed a significant association between NAT2 slow acetylators and risk of anti-TB druginduced liver toxicity [7]. On the other hand, fast acetylators are likely to benefit less from a prescribed drug dose. INH doses 1.5 times the currently recommended doses have been suggested for rapid acetylators [17]. A comparison of responses to TB treatment between slow and rapid acetylators of INH suggested an association between treatment response and rate of inactivation of INH. The difference in the rate of conversion to bacteriological negativity between slow and rapid acetylators was described [18]. 
$\mathbf{A}$

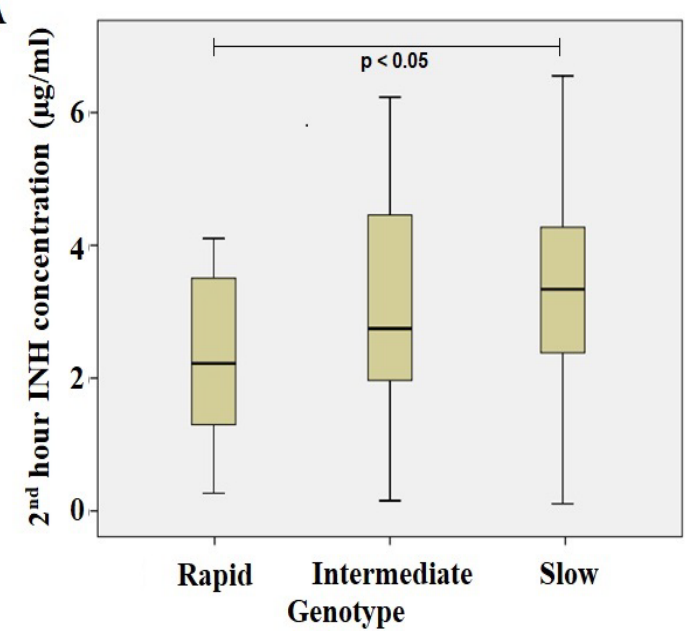

B

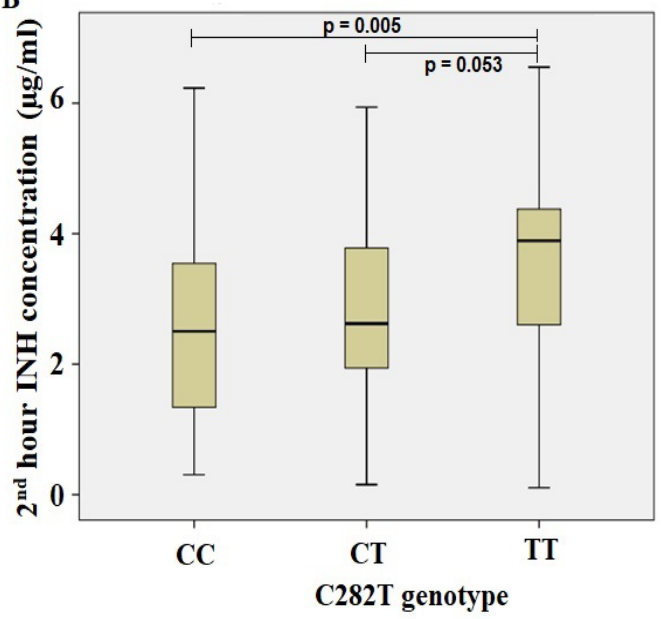

Figure 1 Median two-hour isoniazid concentrations in different genotypes. The vertical bars denote interquartile range. A: genotype of all SNP presented by acetylator capacity of rapid, intermediate, and slow. B: genotype of NAT2(C282T).

In this study, we carried out plasma INH concentrations at two hours after an oral drug administration. Because of logistical and financial difficulties during blood sample collection, the number of time points was limited. When only one sample can be taken, the two-hour post-dosing INH concentrations are the most common used, and INH concentration peaked at two hours in more than 95 per cent of patients in studies [19]. In the literature, the target peak concentration of INH is in the range of $3-6 \mu \mathrm{g} / \mathrm{ml}$ after oral administration of $5 \mathrm{mg} / \mathrm{kg}$ body weight [19]. The drug concentrations observed in our study were lower than those reported in several earlier studies, which could be because of differences in the INH dose used in these studies. Some studies used INH doses of up to $600 \mathrm{mg}$ [20], two times higher than the dose used in this study. We chose the INH dose based on the recommendation of WHO Guidelines for the programmatic management of drug-resistant tuberculosis [21]. Interestingly, a pilot study applied a new INH dosing regimen which takes into consideration NAT2 genotype and body weight and demonstrated potential for subsequent large-scale studies [22].

\section{Conclusions}

Genotyping of TB patients for NAT2 gene polymorphism identified 31.62, 42.65, and $25.74 \%$ patients as slow, intermediate, and rapid acetylators. Two-hour INH levels were significantly different among slow and rapid acetylators. The data from the present study and other published reports suggest that the determination of the NAT2 genotype prior to INH administration is clinically relevant for the prediction of pharmacokinetic variability and the possible adjustment of INH dosing regimens in practice.

\section{Acknowledgements}

This study was supported by a grant from the Vietnam Ministry of Science and Technology and Newton Fund Vietnam (Grant Number HNQT/SPDP/01.06). 
http://wjst.wu.ac.th

\section{References}

[1] World Health Organization. Global Tuberculosis Report 2018. World Health Organization, Geneva, Switzerland, 2018.

[2] $\mathrm{H}$ Mclleron and $\mathrm{M}$ Chirehwa. Current research toward optimizing dosing of first-line antituberculosis treatment. Expert Rev. Anti Infect. Ther. 2018; 17, 27-38.

[3] A Zabost, S Brzezinska, M Kozinska, M Blachnio, J Jagodzinski, Z Zwolska and E AugustynowiczKopec. Correlation of $\mathrm{N}$-acetyltransferase 2 genotype with isoniazid acetylation in Polish tuberculosis patients. Biomed. Res. Int. 2013; 2013, 853602.

[4] P Wang, K Pradhan, XB Zhong and X Ma. Isoniazid metabolism and hepatotoxicity. Acta Pharm. Sin. B 2016; 6, 384-92.

[5] J Azuma, M Ohno, R Kubota, S Yokota, T Nagai, K Tsuyuguchi, Y Okuda, T Takashima, S Kamimura, Y Fujio and I Kawase. NAT2 genotype guided regimen reduces isoniazid-induced liver injury and early treatment failure in the 6-month four-drug standard treatment of tuberculosis: A randomized controlled trial for pharmacogenetics-based therapy. Eur. J. Clin. Pharmacol. 2013; 69, 1091-101.

[6] JM Walraven, Y Zang, JO Trent and DW Hein. Structure/function evaluations of single nucleotide polymorphisms in human N-acetyltransferase 2. Curr. Drug. Metab. 2008; 9, 471-86.

[7] M Zhang, S Wang, B Wilffert, R Tong, DV Soolingen, SVD Hof and JW Alffenaar. The association between the NAT2 genetic polymorphisms and risk of DILI during anti-TB treatment: A systematic review and meta-analysis. Br. J. Clin. Pharmacol. 2018; 84, 2747-60.

[8] IB Kuznetsov, M McDuffie and R Moslehi. A web server for inferring the human Nacetyltransferase-2 (NAT2) enzymatic phenotype from NAT2 genotype. Bioinformatics 2009; 25, 1185-6.

[9] R Weinshilboum. Inheritance and drug response. N. Engl. J. Med. 2003; 348, 529-37.

[10] TL Le, MH Ta, TH Le, AT Le, TLH Duong, VD Hoang and TT Bui. Simultaneous determination of pyrazinamide, rifampicin, ethambutol, isoniazid and acetyl isoniazid in human plasma by LCMS/MS method. J. Appl. Pharmaceut. Sci. 2019; 8, 61-73.

[11] J Yoo, Y Lee, Y Kim, SY Rha and Y Kim. SNPAnalyzer 2.0: A web-based integrated workbench for linkage disequilibrium analysis and association analysis. BMC Bioinformat. 2008; 9, 290.

[12] A Sabbagh, P Darlu, A Langaney and ES Poloni. Haplotype tagging efficiency and tagSNP sets portability in worldwide populations in NAT2 gene. Bulletins et Mémoires de la Société d'Anthropologie de Paris 2007; 19, 1-9.

[13] B Chen, JH Li, YM Xu, J Wang and XM Cao. The influence of NAT2 genotypes on the plasma concentration of isoniazid and acetylisoniazid in Chinese pulmonary tuberculosis patients. Clin. Chim. Acta 2006; 365, 104-8.

[14] GA Ellard. Variations between individuals and populations in the acetylation of isoniazid and its significance for the treatment of pulmonary tuberculosis. Clin. Pharmacol. Ther. 1976; 19, 610-25.

[15] M Kinzig-Schippers, D Tomalik-Scharte, A Jetter, B Scheidel, V Jakob, M Rodamer, I Cascorbi, O Doroshyenko, F Sorgel and U Fuhr. Should we use N-acetyltransferase type 2 genotyping to personalize isoniazid doses? Antimicrob. Agents Chemother. 2005; 49, 1733-8.

[16] N Singh, S Dubey, S Chinnaraj, A Golani and A Maitra. Study of NAT2 gene polymorphisms in an Indian population: Association with plasma isoniazid concentration in a cohort of tuberculosis patients. Mol. Diagn. Ther. 2009; 13, 49-58.

[17] R Kubota, M Ohno, T Hasunuma, H Iijima and J Azuma. Dose-escalation study of isoniazid in healthy volunteers with the rapid acetylator genotype of arylamine $\mathrm{N}$-acetyltransferase 2 . Eur. J. Clin. Pharmacol. 2007; 63, 927-33.

[18] G Ramachandran and S Swaminathan. Role of pharmacogenomics in the treatment of tuberculosis: A review. Pharmgenom. Pers. Med. 2012; 5, 89-98.

[19] A Alsultan and CA Peloquin. Therapeutic drug monitoring in the treatment of tuberculosis: An update. Drugs 2014; 74, 839-54. 
http://wjst.wu.ac.th

[20] AK Hemanth Kumar, K Ramesh, T Kannan, V Sudha, H Haribabu, J Lavanya, S Swaminathan and G Ramachandran. N-acetyltransferase gene polymorphisms \& plasma isoniazid concentrations in patients with tuberculosis. Indian J. Med. Res. 2017; 145, 118-23.

[21] World Health Organization. Companion Handbook to the WHO Guidelines for the Programmatic Management of Drug-Resistant Tuberculosis. World Health Organization, Geneva, Switzerland, 2014.

[22] JA Jung, TE Kim, H Lee, BH Jeong, HY Park, K Jeon, OJ Kwon, JW Ko, R Choi, HI Woo, WJ Koh and SY Lee. A proposal for an individualized pharmacogenetic-guided isoniazid dosage regimen for patients with tuberculosis. Drug Des. Devel. Ther. 2015; 9, 5433-8. 